\title{
Ueber einen neuen pathogenen Parasiten im Blute der Rinder in Süd-Afrika.
}

Von

Dr. W. Kolle,

Bacteriologist to the Government of the Cape of Good Hope.

Gelegentlich meiner Untersuchungen über Rinderpest in R. Koch's Experimentalstation in Kimberley hatte ich Gelegenheit, eine Krankheit des Rindviehes näher zu studiren, die sich nach Verlauf und Verbreitungsbezw. Uebertragungsweise als eine infectiöse kennzeichnete. Zuerst konnte ich diese Krankheit auf der Versuchsstation beobachten, später aber auch ihr Vorkommen in verschiedenen Herden des Districtes Kimberley feststellen. Es kam häufig vor, dass Farmer wegen unaufhaltsamen Sterbens ihres Viehbestandes einige Wóchen nach erfolgreicher Impfung ihrer Rinder mit Rinderpestgalle oder -Blut Rath auf der Station einholten, um der angeblich wieder aufgetretenen Rinderpest Einhalt zu gebieten; es wurde dabei fast stets betont, dass ,die Symptome gar nicht auf Rinderpest passten". Bei genauer Untersuchung stellte es sich meist heraus, dass es sich um die nun genauer zu beschreibende Blutkrankheit handelte. Aus Berichten, die ich aus dem Oranje-Freistaat und verschiedenen Provinzen der Capcolonie gesehen habe, ist die Krankheit, soweit man aus der Schilderung das entnehmen kann, in Südafrika ziemlich verbreitet.

Die Symptome äussern sich in stark remittirendem Fieber, Abmagerung und Fressunlust, bis sich gegen Ende des Lebens ein comatöser Zustand einstellt, in dem die Thiere zuweilen mehrere Tage liegen, ohne Nahrung zu sich zu nehmen. Zuweilen zieht sich der Krankheitsprocess über mehrere Monate hin, öfter führt er in mehreren Wochen zum Tode. Die Mortalität scheint eine ziemlich hohe zu sein, schätzungsweise, da mir genaue Zahlen nicht zu Gebote stehen. Hämoglobinurie oder Blutharnen wird nie beobachtet.

Die pathologisch-anatomischen Veränderungen kennzeichnen sich in auffallender Blässe aller Organe, die ausserdem nach kurzer $\mathrm{Be}$ rührung mit der atmosphärischen Luft einen tiefgelben Farbenton aufweisen, wässeriger Beschaffenheit des Blutes, vergrösserter und weicher, 
blutüberfüllter Milz und Leber. Die übrigen Organe, Nervensystem, Respirations- und Digestionstractus lassen ausser Blässe nichts Abnormes erkennen. Die Nieren sind normal, und in der Harnblase ist nie mit Blut oder Hämoglobin gemisehter Harn zu finden.

Im Blute, das in typischen Fällen völlig wässerig aussieht und.arm an rothen Blutkörperchen ist, konnte ich regelmässig ein morphologisch eigenartiges Gebilde nachweisen. Bringt man einen Tropfen solchen Blutes unter das Mikroskop und betrachtet es in ungefärbtem Zustande, so sieht man in einem Theile der rothen Blutscheiben runde, fast die ganze Zelle ausfüllende blasse Körperchen, die bei Körperwärme amöboide Bewegung zeigen. Im gefärbten Präparate ( $\mathrm{s}$. beifolgende Figur) lässt sich die Morphologie dieser als Parasiten zu deutenden Gebilde besser studiren.

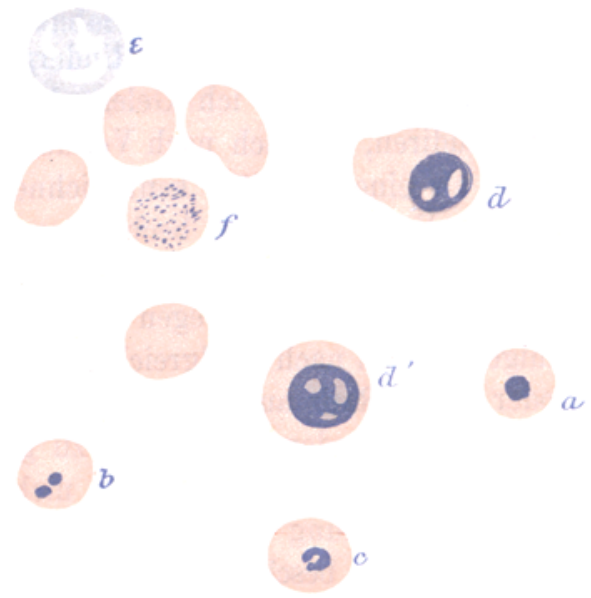

Färbung mit Methylenblan, Gegenfärbung mit Eosin.

a Junge Parasit einzeln. $b$ Junger Parasit doppelt. $c$ Beginnende Vacuolenbildung. $d d^{\prime}$ Ausgewachsene Formen mit Vacuolen. $e$ Freie Parasiten. $f$ Pigmentzellen.

Es zeigt sich hier eine auffallende Aehnlichkeit mit den Malariaparasiten des Menschen, denen sich die hier zu beschreibenden Mikroben auch tinctoriell gleich verhalten. Es soheint, als ob auch diese Parasiten einen Entwickelungscyklus innerhalb der rothen Blutkörperchen durchmachen, um dann nach erfolgter Reife frei zu werden. ${ }^{1}$ Sehr selten finden sich zwei Parasiten, und zwar augenscheinlich nur im Jugendzustande, in einer Blutzelle $(b)$; bei der weiteren Entwickelnng behauptet

1 Die obenstehende, naturgetrene Abbildung verdanke ich der Liebenswürdigkeit des Hrn. Dr. Turner, Medical officer of health for the Colony of the Cape of Good hope, der ganz objectiv mit kunstgeübter Hand eine Wiedergabe der Parasiten nach meinen Präparaten für mich angefertigt hat. 
stets ein Parasit das Feld. Bei den grösseren Formen, offenbar den älteren Stadien im Entwickelungsgange des Parasiten, sind häufig Vacuolen wahrnehmbar $\left(d\right.$ und $\left.d^{\prime}\right)$. In typischen Krankheitsfällen sind während des acuten Stadiums diese grossen, ausgewachsenen Parasiten in der Ueberzahl, die kleinen (Jugend-)Formen dagegen selten. Stets finden sich daneben (bei Färbung, wie hier angegeben) blasse, blaugefärbte Scheiben, die aus tinctoriellen Gründen (sie sind nur im Blute der an dieser Krankheit leidenden Rinder vorhanden) nicht als histologische Elemente des Blutes aufgefasst werden können, sondern wohl als freie, mit Vacuolen ausgestattete Formen der Parasiten mit Sicherheit gedeutet werden dürfen. Wie bei der Malaria der Menschen, findet sich bei dieser malariaähnlichen Krankheit der Rinder Pigment in einem Theile der rothen Blutzellen ( $f$ ), besonders nach Ablauf einer Fieberexacerbation und in chronischen Fällen. Es stammt wohl zweifellos von den. zerfallenen Parasiten, denn man sieht in solchen Fällen auch in Zerfallsprodukten der Parasiten ausserhalb der rothen Blutzellen Pigmentkörnchen.

Der Entwickelungsgang der Parasiten würde aber so zu denken sein, dass ein durch Zerfall eines ausgewachsenen Parasiten entstandenes Theilstück, das ich morphologisch allerdings noch nicht habe nachweisen können, in eine Blutzelle eindringt (zuweilen auch zwei). Hier entsteht aus dem als Spore zu denkenden Stückchen ein neuer Parasit, der zunächst klein ist, dann wächst und zerfällt, wahrscheinlich meist innerhalb der ihn überlebenden Blutzelle.

Ein ähnlicher Parasit ist weder von mir noch Anderen, welche das Blut von Rindern in Südafrika häufig und lange Zeit untersucht haben (R. Koch, G. Turner, Bordet und Danysz u. A.), je im Blute weder von gesunden, noch in demjenigen an anderen Krankheiten leidender Rinder gesehen worden. Zur Differentialdiagnose käme nur der Parasit des Texasfiebers (Baber, Th. Smith u. A.) in Betracht. Man könnte denken, dass es sich hier um eine starke morphologische Varietät des Erregers einer auch klinisch modificirten Form des Texasfiebers (in Südafrika allgemein unter dem Namen ,red water" bekannt) handele. Aehnliche Erkrankungen sind beobachtet: in Rumänien (Babes, Hämoglobinurieseuche; in Deutschland (Weisser, Maasse n, Hamburg); in Finnland (Ali Krogius v. Hellens, Hämoglobinurie); in Sardinien (Sanfelice, Loi, Hämatinurie), in der Campagna di Roma (Celli u. Santori, Rindermalaria). Aber die Unterschiede in der Morphologie der Parasiten, dem klinischen Verlaufe der Krankheit und den pathologisch-anatomischen Veränderungen bei diesen Texasfiebererkrankungen einerseits und der hier in Rede stehenden Krankheit andererseits sind denn doch zu gewaltig, als dass sie den Gedanken einer Identität beider Parasiten Raum geben könnten. 
Ich habe reichlich Gelegenheit gehabt, Texasfieber in Südafrika zu studiren und kann auf Grund meiner Beobachtungen sagen, dass auch im Süden Afrikas das Texasfieber (red-water) klinisch und bezüglich seiner Parasiten die Eigenschaften zeigt, die nach den Beschreibungen von Babes und Th. Smith als bekannt vorauszusetzen sind. Der Parasit (Pyrosoma bigeminum) wurde fast stets zu zweien innerhalb einer Blutzelle gefunden, und wies die typische Keulen- oder Birnenform auf. Runde Formen wurden so gut wie nie, Formen, welehe das rosa Blutkörperchen ausfüllten, wie unser Parasit, nie gefunden. Pigmentzellen oder Pigment in dem P. bigeminum selbst wurden nie beobachtet. In der Niere fanden sich die rothen Blutkörperchen um das Doppelte mehr befallen, als im circulirenden Blute und den übrigen Organen. Hämoglobinurie wurde während des Lebens häufig gesehen, bei der Obduction aber wurde stets mit Hämoglobin gemischter Harn in der Harnblase gefunden.

Im Gegensatz hierzu ist bei der hier meines Wissens zum ersten Male beschriebenen Blutkrankheit der südafrikanischen Rinder, der ich den Namen Febris malarioformis beilegen möchte, weder während des Lebens der Thiere oder nach dem Tode Hämoglobinurie nachweisbar; die Parasiten finden sich nie in dem Blutkörperchen der Thiere $m e h r$, als in denen des circulirenden Blutes und der Organe; es werden Pigmentzellen fast nie vermisst. Dazu kommt die Verschiedenartigkeit der Parasiten, die zudem amöboide Beweglichkeit aufweisen.

Dies alles genügt, um die beschriebene Krankheit als eine solche sui generis hinzustellen, als deren Ursache der von mir gefundene Parasit wohl mit Sicherheit betrachtet werden kann. Für das zur Gewinnung des Rinderpestserums nothwendige Immunisirungswerk, welches jetzt noch auf der Experimentalstation in Kimberley im Grossen durchgeführt wird, musste das Auftreten der Blutkrankheit als eine ernste Sache aufgefasst werden, weil die Zahl der daran erkrankten Thiere eine nicht unerhebliche, und die Mortalität unter dem erkrankten Vieh eine hohe (50 Procent) war. Es lag der Gedanke nahe, dass durch die Einspritzung des Blutes ron rinderpestkranken Thieren zum Zwecke der Immunisirung die Krankkeit von einem Thiere auf das andere übertragen würde. Da seit der Zeit, wo jede Blutprobe vor der Injection sorgfältig mikroskopisch untersucht wird, Neuerkrankungen unter den mit solchem Blute geimpften Thiere nicht mehr vorgekommen sind, so hat eine Annahme dadurch sehr an Wahrscheinlichkeit gewonnen gegenüber anderen Vermuthungen, wonach die Uebertragung des Infectionsstoffes ähnlich, wie sie beim Texasfieber durch Vermittelung blutsaugender Zecken (Ixoder bovis) angenommen wird, stattfinden würde. 